\title{
Habitat selection at settlement endures in recruitment time series
}

\author{
Jonathan N. Blythe*, Jesús Pineda \\ Biology Department, Woods Hole Oceanographic Institution, Woods Hole, Massachusetts 02543, USA
}

\begin{abstract}
Metamorphosis from a pelagic to a benthic stage is a critical transition in the life cycle of sessile marine invertebrates. The barnacle Semibalanus balanoides attaches permanently during settlement, and once attached, its gross location in the adult habitat is fixed. The partitioning of benthic habitat among barnacles in a recruit cohort is often mediated by settlement timing because early settlement preempts later settlement. We found that barnacles that settled earlier had a higher chance of survival to reproductive age. Additionally, there was a marked preference for some settlement locations over others as indicated by the order that different quadrats were occupied. Location of settlement resolved on a daily timescale over $34 \mathrm{~d}$ within 1 site had an enduring influence on which individuals survived to adulthood up to 12 mo later. Furthermore, adult density from a recruit cohort was highly correlated with the timing of settlement. Therefore, habitat selection behavior at settlement may account for a large degree of variability in recruit survival through adulthood in sessile marine invertebrates.
\end{abstract}

KEY WORDS: Larval settlement behavior · Priority effects · Habitat discrimination · Recruitment window

Resale or republication not permitted without written consent of the publisher

\section{INTRODUCTION}

Research on the demography of benthic marine invertebrates such as the intertidal barnacle Semibalanus balanoides has been a focus in marine ecology for several decades, providing an example of how marine populations may be regulated. Changes in S. balanoides population density correlate at geographic scales (Southward \& Crisp 1956, Burrows et al. 2002). Recruitment can be important to changes in population density according to the concept of supply limitation in marine communities (Underwood \& Fairweather 1989). However, ecological interactions such as predation modulate patterns of recruitment variability in $S$. balanoides (Menge 1991), and a demographic analysis for this species suggests that survival probability, as for juvenile and adult stages, is more important than recruitment for explaining changes in population density (Svensson et al. 2004).

Settlement is the point in time when a larval barnacle arrives in the adult habitat. Larvae metamorphose after settlement, and as juveniles, barnacles accumulate in the benthic habitat. This period of influx of propagules to the adult habitat is well defined in species like Semibalanus balanoides that have distinct settlement seasons. The influx of settlers may be so great that it saturates substrate resources. Metamorphs and juveniles, called recruits, may soon cover every suitable surface in the rocky intertidal habitat. An experiment that supports this idea induces settlement by clearing substrate area previously occupied by recruits (Connell 1985). In $S$. balanoides, total settlement is a reliable measure of the number of recruits at the end of the settlement season, but settlement density does not necessarily predict adult density (Connell 1985). The number of juveniles eventually declines from predation and intraspecific competition (Connell 1961), sometimes many months after settlement (Jenkins et al. 2008). However, only a small number of recruits need to survive in order to saturate the substrate when they mature and reach adulthood. Available substrate area may limit the rate at which recruits occupy a habi- 
tat (Gaines \& Roughgarden 1985), but area may be a limiting resource to adult barnacles in a different way. In fact, experimentation has demonstrated that the actual feature of a substrate area that is limiting to $S$. balanoides settlement is the number of suitable settlement sites (Hills \& Thomason 1996) rather than area per se, and settlement in another intertidal barnacle species could become saturated at relatively low recruit densities (Raimondi 1990).

Semibalanus balanoides becomes sessile at settlement when the cyprid larval stage attaches to the substrate. Prior to settlement, the cyprid is quite mobile and exhibits a variety of searching behaviors on benthic surfaces (Walters et al. 1999). In addition to surface exploration, a cyprid may actively reject a substrate by returning to the water column where it may have a better chance to subsequently encounter other substrates that are more suitable (Berntsson et al. 2004). The cyprid exhibits habitat selection behavior including gregariousness (Knight-Jones 1953), rugosity preference (Wethey 1984), and territoriality (Crisp 1961). By contrast, sessile individuals of $S$. balanoides have extremely limited mobility and their gross location and habitat will be largely determined by these habitat selection behaviors at settlement. Barnacles can use cues for habitat detection without necessarily affecting survival in the juvenile and adult stages (Stamps \& Krishnan 2005). Some barnacles settle in response to a mucus cue secreted by a barnacle predator (Raimondi 1988), which may enhance short-term survivorship, but discounts the long-term fitness of juvenile and adult stages (but see Johnson \& Strathman 1989). However, some habitat features that are apparently preferred by settlers are also associated with enhanced survival probability for the juvenile and adult stages (Minchinton \& Scheibling 1993). Survival of recruits to adulthood is hypothetically determined by habitat selection behavior when larvae transition to the benthic habitat during settlement.

We measured habitat selection at settlement and the corresponding fitness consequences, measuring which individuals survived through adulthood. Although we did not observe habitat selection behaviors directly, we recorded patterns of when and where individuals settled. Hypotheses were constructed based on simple null assumptions about the order of settlement, and inferences were made on processes occurring during habitat selection that promoted survival. The first hypothesis was that individuals that survived to adulthood settled early during the settlement season, which was tested by comparing the observed settlement order for adults against a null expectation that all settlers had an equal chance of survival to adulthood. The second hypothesis was that different quadrats were settled in order of habitat preference, for example if settlers preferred habitat occupied by adult conspecifics typical of gregarious settlement behavior (e.g. Kent et al. 2003). The hypothesis was tested by comparing the order of settlement between quadrats against the null expectation that there was no difference in the progression of how quadrats were settled. A novel statistic, the Time Average Survivor's Settlement Order (TASSO), is defined and is particularly instrumental in these contrasts with statistics based on null assumptions. The evidence presented here indicates that habitat selection at settlement determines in large part the survival of recruits to adulthood.

\section{MATERIALS AND METHODS}

Twelve quadrats were located on large granite boulders emerging from a cobble beach at Park Road in Woods Hole, Massachusetts (USA), and detailed descriptions of this site are available in previous recruitment studies (Pineda et al. 2002, 2005, 2006). Quadrats were located centrally in the range of adult barnacles for each haphazardly selected boulder surface. Nearly flat surfaces for quadrat locations were identified by pressing a compact disk $12 \mathrm{~cm}$ in diameter against the surface. Features of the quadrat surfaces, such as relative location and orientation are listed in Table 1. The
Table 1. Quadrat habitat characteristics. Westing: projected distance west along-shore from the easternmost quadrat. Elevation: vertical distance from mean low low water mark. Perimeter: perimeter of the boulder surface at the quadrat's approximate elevation. Direction: direction that the quadrat is facing. Horiz. deg.: angle from the horizon that the quadrat is facing, where negative values indicate downwards

\begin{tabular}{|lccccc|}
\hline Quadrat & $\begin{array}{c}\text { Westing } \\
(\mathrm{m})\end{array}$ & $\begin{array}{c}\text { Elevation } \\
(\mathrm{m})\end{array}$ & $\begin{array}{c}\text { Perimeter } \\
(\mathrm{m})\end{array}$ & Direction & $\begin{array}{c}\text { Horiz. } \\
\text { deg. }\end{array}$ \\
\hline 1 & 0 & 0.57 & 5.56 & $\mathrm{E}$ & 21 \\
2 & 1.6 & 0.23 & 5.58 & $\mathrm{~W}$ & 56 \\
3 & 3.8 & 0.35 & 4.51 & $\mathrm{SW}$ & -39 \\
4 & 4.1 & 0.28 & 4.22 & $\mathrm{~S}$ & 11 \\
5 & 7.9 & 0.42 & 6.82 & $\mathrm{E}$ & 65 \\
6 & 12.3 & 0.39 & 5.41 & NNW & -8 \\
7 & 30.4 & 0.19 & 2.34 & SE & 20 \\
8 & 34.4 & 0.65 & 7.41 & ESE & 8 \\
9 & 36.0 & 0.68 & 7.41 & NW & -2 \\
10 & 59.4 & 0.55 & 7.27 & E & -6 \\
11 & 61.9 & 0.60 & 7.27 & NW & 3 \\
12 & 70.4 & 0.51 & 3.55 & NNW & 49 \\
\hline
\end{tabular}


fine-scale features of the quadrat surfaces varied, having a range of rugosity typical of weathered, natural, granite surfaces. Quadrats were $2.5 \times 1.75 \mathrm{~cm}$ and were marked at the ends of their $3 \mathrm{~cm}$ diagonal with drill holes holding green screw anchors. In December 2005, adult barnacles were scraped off a $2 \times 1.5 \mathrm{~cm}$ area centrally located between the 2 green markers using a flathead screwdriver. Adults in the surrounding habitat were left undisturbed, and were monitored throughout 2006 by counting the number of individuals in a $10 \times 7.5 \mathrm{~cm}$ area centered on each quadrat at 2 wk to 1 mo intervals.

We recorded a recruitment time series from January to December 2006, taking photographs over 150 consecutive days spanning the settlement season between January and May. Settlement was measured by comparing sequential photographs of the quadrat surface, using a $2.5 \times 1.75 \mathrm{~cm}$ area between the edges of the green markers that marked the boarders of the quadrat. Day 1 for all time series was defined as the first day that a barnacle settled on any of the quadrats. Winter settlement is typical for this region (Pineda et al. 2005), although settlement typically begins during the spring in other portions of the barnacle's range (Wethey 1986). We extended the recruitment time series beyond the settlement season by tracking individuals in photographs taken monthly between May and December. We did not verify whether surviving individuals reproduced in December, but $95 \%$ of Semibalanus balanoides at 2 nearby intertidal locations had live embryos in December of a previous year (J. Pineda unpubl. data). Therefore, we called these surviving individuals adults, because at this age they are mature and capable of reproduction. A result from an analysis of settlement in 2002 at this site indicated that settlers from a short segment of the settlement season survived to adulthood, and the range of settlement dates that resulted in survival to adulthood was identified as a recruitment window (RW) (Pineda et al. 2006). The purpose of the present study was to identify how survival depends on habitat selection at settlement. Therefore, we focused on the first $34 \mathrm{~d}$ of the settlement season, which includes all individuals that settled during the winter of 2006 and survived to adulthood (i.e. the winter RW).

Since we had a finely resolved settlement time series, we could calculate detailed information for individual settlers, such as the order in which individuals occupied the quadrat surface. Each settler from the winter RW was assigned an index value, $N$. Cumulative settlement was calculated for each day by summing the number of settlers since Day 1 and across all 12 quadrats. Settlement order $O_{N}$ of individual $N$ was the cumulative settlement value on the day of settlement. However, when more than 1 individual settled in a given photographic interval, $O_{N}$ was approximated as the cumulative settlement from the previous day plus half of the settlement for the contemporary day. Settlement order was also calculated at the quadrat level, and each individual settling within a quadrat was assigned a unique index value for that quadrat, $n$. Settlement order $o_{n}$ for individual $n$ was calculated based on the cumulative settlement like for the site wide value, $O_{N}$, except using a different cumulative settlement value calculated for settlement only within its quadrat of residence.

The fine resolution of our recruitment time series allowed us to keep track of which individuals settled during the winter RW and survived to adulthood. We counted the total number of survivors, $R$, and each survivor was assigned a unique index value, $I$. $O_{I}$ is settlement order for individual $I$. The set of $O_{I}$ is contained in the set of all settlers' settlement order, and they are the orders of settlement for individuals that survived to adulthood;

$$
\left\{O_{I}\right\} \subset\left\{O_{N}\right\}
$$

Taking this subset of values, we calculated the Site and Time Average Survivor's Settlement Order (SATASSO);

$$
\text { SATASSO }=\sum_{I} O_{I} / R
$$

Quadrat level statistics were also calculated based on when individual survivors from a quadrat settled. The number of individuals settling during the winter RW that survived to adulthood, $r$, was calculated for each quadrat. Each individual that survived to adulthood was assigned an index value, $i$, unique for each quadrat. Individual $i$ 's settlement day $t_{i}$ was calculated. We calculated summary statistics of the first, $t_{1}$, and mean $t_{i}$ in each quadrat. Settlement order $o_{i}$ was also calculated for each survivor $i$ within a quadrat. The set of $o_{i}$ for a quadrat is contained in the set of settlers' settlement orders from a quadrat, and they are the orders of settlement for individuals that survived to adulthood within a quadrat;

$$
\left\{o_{i}\right\} \subset\left\{o_{n}\right\}
$$

Based on a quadrat's specific values for $o_{i}$, we calculated its Time Average Survivor's Settlement Order (TASSO).

$$
\text { TASSO }=\sum_{i} o_{i} / r
$$

The hypothesis that early settlers tended to survive to adulthood was tested by computationally generating expected values for the SATASSO and TASSO statistics. The SATASSO was compared to a null statistic assuming that every individual settling during the winter RW had an equal chance of survival to adulthood. Using a custom generated MATLAB code, $R$ set- 
tlers from the set of $N$ were subsampled at random, and their $O_{N}$ were averaged to generate a null statistic for the expected order. The null hypothesis was rejected if the SATASSO was less than $95 \%$ of 1000000 null statistics. Since this was a 1-sided statistical test, rejection of the null hypothesis would support the alternative that barnacles that survived to adulthood tended to settle early. In addition to testing this hypothesis for settlement across all quadrats, the hypothesis test was also conducted within all 12 quadrats separately. Similarly, $r$ settlers were subsampled from the set of $n$ using MATLAB code. We excluded settlers that had a value of $o_{n}$ greater than the greatest value for $o_{i}$ for each quadrat, enhancing the power of the statistical test in quadrats where the last survivor settled prior to the end of the winter RW. The settlement order, $o_{n}$, for the null subsamples of settlers was averaged to generate null statistics, and the hypothesis was rejected if the TASSO was less than $95 \%$ of the 1000000 null statistics generated for each quadrat.

We tested the null expectation that settlement was distributed homogeneously across the site. Indices of settlement heterogeneity have previously been defined by a ratio of settlement density within a location divided by settlement density among a group of locations (Raimondi 1990, Hills \& Thomason 1996). However, we conducted a novel analysis of heterogeneous settlement, deriving an index of settlement heterogeneity based on settlement order. Settlement order $O_{i}$ is individual $i$ 's site-wide settlement order value. The set of $O_{i}$ is contained in the set of all survivors' site level settlement orders, reflecting the site level settlement orders for survivors only from within a quadrat;

$$
\left\{O_{i}\right\} \subset\left\{O_{I}\right\}
$$

We divided the sum of $O_{i}$ by the number of survivors in a quadrat, $r$, and the number of quadrats at the site, $S$, to generate a mean-field value for the settlement order for each quadrat. We evaluated the distribution of settlement in each quadrat by subtracting the quadrat's mean-field value from the TASSO. Intuitively, if the TASSO is particularly high or particularly low compared to the mean-field value, then this would contribute to a larger or smaller distribution index (DI):

$$
\mathrm{DI}=\sum_{i} o_{\mathrm{i}} / r-\sum_{i} O_{i} / r S
$$

We correlated 2 variables with the DI to examine the hypothesis that larvae exhibited substrate preferences at settlement. We could not correlate the DI with quadrat habitat quality, although this would be an ideal test of the habitat selection hypothesis, since it is not possible to measure habitat quality directly. Instead, we collected information about the timing and location of settlement enduring in the recruitment time series. However, settlement timing is only a proxy for habitat selection, which assumes that settlement timing reflects the first occasion when a larval barnacle makes the hypothesized habitat selection for a particular settlement location. We correlated the variable $t_{1}$, the first settler occupying a quadrat that subsequently survived to adulthood, with the DI to test the hypothesis of habitat selection. The distribution index and $t_{1}$ are an indication of what order and when quadrats were settled, respectively. However, these statistics are independent because the DI accounts for all individuals, $i=\{1,2,3 \ldots r\}$, and $t_{1}$ is the settlement timing for a single individual $(i=1)$. Furthermore, the DI was correlated with the conspecific adult density to test the hypothesis of habitat selection involving gregarious settlement behavior. Adult conspecifics induce settlement in larval barnacles, because they are a source of the conspecific cue for barnacle settlement (Crisp \& Meadows 1962). Both $t_{1}$ and the conspecific adult density were regressed against the DI by multiple linear regression to assess the hypothesis that settlers discriminated between habitat while exhibiting larval settlement behavior.

\section{RESULTS}

The settlement season spanned 138 d between 8 January and 25 May 2006, and the highest value for the settlement rate was recorded at 14.7 settlers $\mathrm{cm}^{-2}$ on the second to last day of the winter RW (Fig. 1). Settlement continued at a high rate for a few days after the winter RW, but none of these settlers survived to adulthood. Later in the winter, the settlement rate dropped to 0 and was punctuated occasionally by settlement events for the

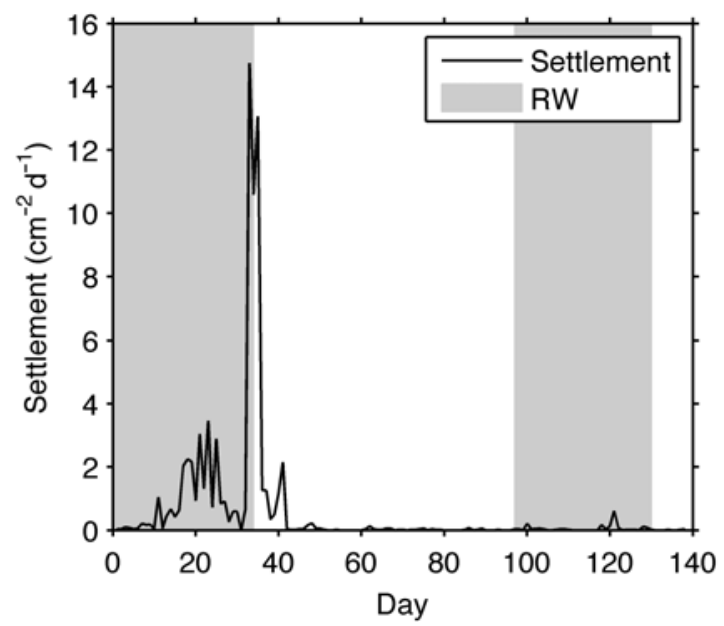

Fig. 1. Semibalanus balanoides. Recruitment windows (RW) and settlement over the 2006 settlement season. The 2 shaded regions indicate the range in days of the winter (left) and spring (right) RW. Settlement density is all individuals settling during $1 \mathrm{~d}$ intervals in 12 quadrats, scaled by the total area 
remainder of the settlement season, including a spring RW. The pattern of survivorship of winter settlement immediately after the winter RW and spring settlement during the spring RW could variously be explained by the availability of settlement substrate. Substrate was nearly saturated with recruits by the end of the winter RW, and the scarcity of available substrate was lessened later by the beginning of the spring RW due to mortality of recruits during the intervening part of the settlement season. This posed a problem for our analysis since our proxy for habitat selection requires that each settlement event is the earliest settlement event for a particular settlement site. However, if mortality should occur, then more than 1 settlement event could occur in each settlement site, and subsequent re-occupation would diminish how precisely settlement timing actually reflects the first expression of habitat selection for each settlement site. Settlement during the spring RW occurred on substrate previously occupied by other settlers. Therefore, we focused our analysis on recruitment originating from the winter RW, because recruitment from the spring RW did not conform with this assumption of our analysis.

The SATASSO was smaller than expected, assuming that all settlers from the winter RW had an equal chance of survival. TASSO values were smaller than expected for 9 of the quadrats. This hypothesis test was based on the null distribution for the TASSO values, computed by averaging the settlement order for random subsets of settlers $n$ from within a quadrat. Thus, 3 of the quadrats had TASSO values that were not significantly different than if random samples of settlers had survived to adulthood. However, 2 of these quadrats had too few settlers $n$ and survivors $r$, generating expected distributions that were inadequate for a conclusive hypothesis test.

The DI was correlated with 2 variables measured from photographs taken during the winter RW: the adult abundance in the area surrounding the quadrat
$\left(\mathrm{R}^{2}=0.49\right)$, and $t_{1}$, the first day of settlement that resulted in survival to adulthood in a quadrat $\left(R^{2}=\right.$ 0.86; Fig. 2A,B). Together these variables explained $95 \%$ (adjusted $\mathrm{R}^{2}=0.95$ ) of the variance in the DI among the 12 quadrats monitored at Park Street (Fig. 2C). The F-ratio for the multiple regression was $107(p<0.001)$. The intercept was not significantly different from 0 , but the adult coefficient was estimated at $0.22(\mathrm{p}<0.001)$, while the coefficient for $t_{1}$ was estimated at $-1.7(\mathrm{p}<0.001)$.

The number of individuals surviving to adulthood in quadrats from the winter RW varied between 1 and 21 individuals with a mean $\pm \mathrm{SD}$ of $9.6 \pm 6$.3. This number of survivors represents $4.2 \%$ of all individuals that settled during the winter RW. The duration in days between $t_{1}$ and the mean of $t_{i}$ explained $83 \%$ of the variance in the abundance of recruits surviving to adulthood (Fig. 3). The 4 quadrats that have large positive leverage in this correlation also had the earliest first arrival days.

\section{DISCUSSION}

If individual cyprids discriminate suitable settlement sites based on habitat quality, then these settlement choices could endure in the barnacle population by determining which recruits survive to adulthood. For example, barnacles that arrive earlier in the settlement season might have a higher probability of survival to maturity (Raimondi 1990, Pineda et al. 2006). Our data support this conclusion, since the TASSO was significantly smaller than expected by chance for 9 out of 12 quadrats. Barnacles occupied some quadrats before others, and quadrats had variable DI values. A quadrat with a high DI value has a relatively high TASSO, and settling in another quadrat would be more strategic from the perspective of minimizing preemption. How-
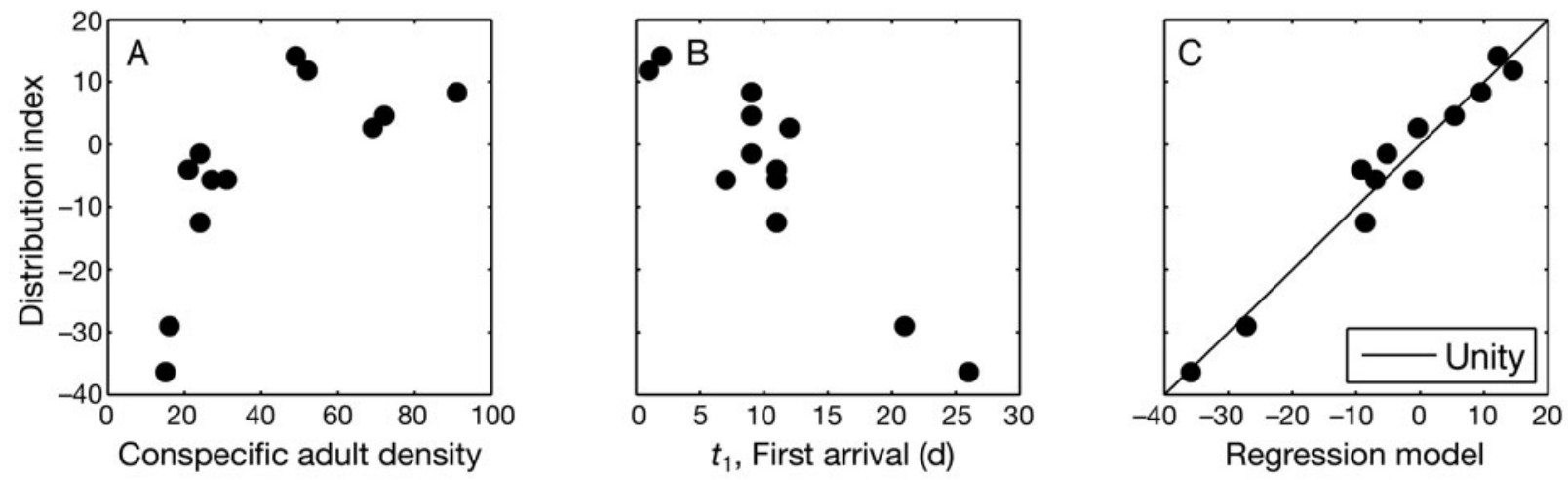

Fig. 2. Semibalanus balanoides. Correlates to spatial variability in recruitment time series. (A) Adult density in the area surrounding each quadrat (adults $75 \mathrm{~cm}^{-2}$ ) during the settlement season, and (B) first arrival day, $t_{1}$, are correlated with the distribution index. (C) A multiple linear regression model ( $0.22 \times$ conspecific adult density $\left.-1.7 \times t_{1}\right)$ of these 2 variables explains $95 \%$ of the variance in the distribution index 


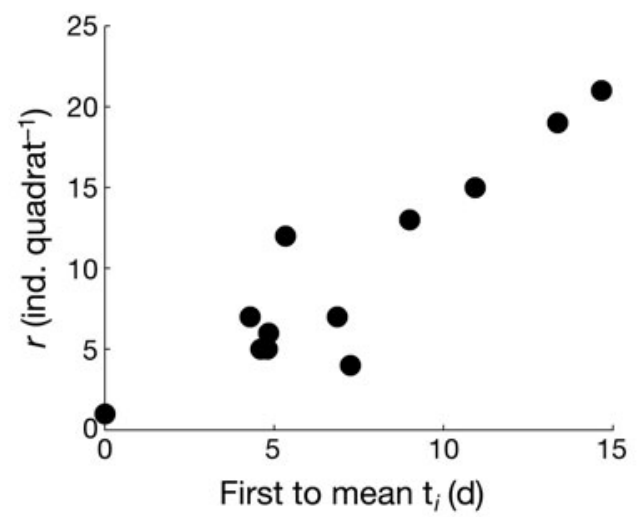

Fig. 3. Semibalanus balanoides. Timing and abundance of adults from the winter RW. The first to mean arrival days is the duration of time between settlement days for individuals that survived to adulthood (i.e. mean $t_{i}-t_{1}$ ), which explains $83 \%$ of the variance in adult abundance. The regression is significant ( $\mathrm{p}<0.001)$, with an $F$-ratio of 52 . The 4 quadrats that have large positive leverage are quadrats where the first adult $(i=1)$ has a settlement order of 1 or 2 at the quadrat level and among the earliest settlement order values for the site as a whole

ever, if larvae exhibit habitat selection behavior at settlement, selecting a high DI quadrat could be strategic if it contains preferred habitat of relatively high quality. Larger DI values correlated with conspecific adult abundance (Fig. 2A), indicating gregarious settlement. The order in which quadrats were settled, as indicated by the DI, is correlated with the timing of a single settlement event, i.e. the first settler that survived to adulthood (Fig. 2B). Hypothetically, settlement by individuals could reflect their preference for certain habitats, or alternatively it could depend on mechanisms of larval delivery (Jonsson et al. 2004). High supply could affect a high rate of settlement in some quadrats plausibly accounting for instances of early first arrival and a high DI. However, this alternative hypothesis fails to account for the pronounced preemption pattern from the recruitment time series. Moreover, heterogeneity in the quality of larvae settling at any given time does not explain these patterns, since quadrats were probably exposed to a well-mixed, homogeneous larval pool. Further evidence for habitat selection is that settlement timing for individuals that survived to adulthood correlated with their abundance (Fig. 3). Temporal and spatial variability in settlement might correspond to variability in quadrat habitat quantity and quality. Underlying quadrat variability may ensure that habitat selection at settlement has an enduring influence in recruitment time series well after the settlement season.

The quadrat is a marked substrate area that is among the most basic empirical tools that ecologists have developed to measure settlement in the rocky intertidal zone. Quadrats are a deceptively simple tool, since there are a variety of commonly used quadrat types that likely influence settlement patterns. For example, in quadrats where clearing of habitat occurs prior to measuring settlement, the shape (Raimondi 1990) and size (Jeffery 2000) of the clearing are 2 variables to which settlement is sensitive. The commonly cited reason for quadrat shape and size effects is larval attraction to conspecific adults, which may explain a large degree of variability in settlement density (Kent et al. 2003). Even if quadrat shape or conspecific adult density were controlled for, we still could not assume that standardized quadrats are a standard sampling unit for settlement. More detailed analyses of quadrat surfaces reveal that settlers preferentially occupy microhabitats within quadrats (Wethey 1984), which vary due to the material of surfaces found in the rocky intertidal (Herbert \& Hawkins 2006) and are associated with recruit density (Hills \& Thomason 1996). Quadrats may contain different quantity or quality of habitat that should be quantified more directly to better understand the recruitment variability of sessile marine invertebrates.

The TASSO described herein can contribute to our understanding of what sets the timing of the RW, as it indicates how habitat is ultimately distributed in a recruit cohort. Hypothetically, this ultimate distribution of benthic resources reflects important habitat variability within and between quadrats at a site. Small-scale spatial variability in larval settlement has been described before in the intertidal barnacle Tesseropora rosea (Caffey 1985). Settlement in T. rosea was not saturating since settlement could not be induced by clearing substrate area during the settlement season, and in that study settlement density set adult abundance. On the other hand, in Semibalanus balanoides, settlement is saturating, and settlement density did not set adult abundance (Connell 1985). Settlement density could mediate vital rates such as fecundity in S. balanoides (Wethey 1983, Hills \& Thomason 2003a,b), but where all habitats are typically saturated with recruits during the settlement season, underlying habitat variability may be important for explaining variable survival to adulthood. For example, survivor abundance, $r$, was correlated to survivor settlement timing, $t_{i}$ (Fig. 3 ). We propose that habitat resource partitioning in a recruitment cohort when early arriving settlers select the highest quality habitats and subsequent settlers occupy other sites (Raimondi 1991, Bertness et al. 1992) explains these patterns that endure from settlement to maturity. These results support the hypothesis that the habitat selected at settlement causes variable survivorship of recruits, determining their survival to adulthood.

Generalizations should not be made based on any single experiment or observation, because alternative 
hypotheses also need to be examined (Underwood \& Denely 1984). For example, a variety of other processes have been hypothesized to affect the timing of the RW, including environmental changes independent of when barnacles settle, or energetics and growth dynamics before or after settlement (Pineda et al. 2006). We did not collect measurements to rule out these alternative hypotheses. However, the enduring settlement patterns in recruitment time series are consistent with the hypothesis that this pattern is caused by habitat selection at settlement. These patterns may hold for other species that exhibit habitat selection at settlement, and may also occur in species that modify which habitat they occupy after settlement. The survival advantage individuals gain from settling in superior habitat could result directly from the access to that habitat or indirectly if the benefits of settlement habitat quality propagate to later life stages through one of these alternative mechanisms. These questions are important to the theory of marine animal population regulation. Measurements tracking individuals from settlement to adulthood are necessary to identify settlement patterns that endure in recruitment time series, but these measurements are difficult to conduct in field populations of marine animals.

Habitat discrimination is an interesting and potentially common feature of sessile marine animal life histories. For example, the time when larvae lose selectivity may be an important benchmark in recruitment time series (Blythe 2008). Hypothetically, larvae may lose selectivity as a direct consequence of decreasing suitable habitat availability (Toonen \& Tyre 2007). More likely, larvae lose selectivity only after delaying settlement, because they have not yet encountered suitable habitat (Jarrett 1997). Repeated settlement attempts during habitat search may have additional implications for settlement patterns, e.g. the intensification effect in the case that larvae are retained in a habitat patch (Pineda \& Caswell 1997). Another emergent property of repeated larval search is the advection of larvae from low- to high-quality habitat patches that relies on a mechanism resembling the random walk with habitat-dependent kinesis. Studying the mechanism of habitat selection in sessile marine invertebrates should help support or refute assertions based on models of optimal strategy (Stamps et al. 2005). Additionally, intertidal barnacles may be an ideal system to test whether settlement time series reflect optimal exploitation of limited habitat resources when preemptive effects mediate the larval habitat discrimination in benthic marine invertebrates.

Acknowledgements. We thank D. Rothman and V. Starczak for discussion on statistical analyses and interpretation of the data, and V. Starczak for a critical review of this manuscript.
Comments from A. J. Underwood and 3 anonymous reviewers helped improve the manuscript. H. M. Blythe provided assistance with field work and photograph analyses. Graduate fellowship support was provided to J.N.B by the American Society for Engineering Education and the Academic Programs Office at the Woods Hole Oceanographic Institution.

\section{LITERATURE CITED}

> Berntsson KM, Jonsson PR, Larsson AI, Holdt S (2004) Rejection of unsuitable substrata as a potential driver of aggregated settlement in the barnacle Balanus improvisus. Mar Ecol Prog Ser 275:199-210

> Bertness MD, Gaines S, Stephens EG, Yund PO (1992) Components of recruitment in populations of the acorn barnacle Semibalanus balanoides (Linnaeus). J Exp Mar Biol Ecol 156:199-215

Blythe JN (2008) Recruitment of the intertidal barnacle Semibalanus balanoides; metamorphosis and survival from daily to seasonal timescales. PhD thesis, Massachusetts Institute of Technology/Woods Hole Oceanographic Institution (Joint Program in Biological Oceanography), Woods Hole, MA

- Burrows MT, Moore JJ, James B (2002) Spatial synchrony of population changes in rocky shore communities in Shetland. Mar Ecol Prog Ser 240:39-48

Caffey HM (1985) Spatial and temporal variation in settlement and recruitment of intertidal barnacles. Ecol Monogr 55:313-332

Connell JH (1961) Effects of competition, predation by Thais lapillus, and other factors on natural populations of the barnacle Balanus balanoides. Ecol Monogr 31:61-103

Connell JH (1985) The consequences of variation in initial settlement vs. post-settlement mortality in rocky intertidal communities. J Exp Mar Biol Ecol 93:11-45

Crisp DJ (1961) Territorial behaviour in barnacle settlement. J Exp Biol 38:429-446

Crisp DJ, Meadows PS (1962) The chemical basis of gregariousness in cirripedes. Proc R Soc Lond B Biol Sci 156: $500-520$

- Gaines S, Roughgarden J (1985) Larval settlement rate: a leading determinant of structure in an ecological community of the marine intertidal zone. Proc Natl Acad Sci USA 82:3707-3711

Herbert RJH, Hawkins SJ (2006) Effect of rock type on the recruitment and early mortality of the barnacle Chthamalus montagui. J Exp Mar Biol Ecol 334:96-108

Hills JM, Thomason JC (1996) A multi-scale analysis of settlement density and pattern dynamics of the barnacle Semibalanus balanoides. Mar Ecol Prog Ser 138:103-115

Hills JM, Thomason JC (2003a) Recruitment density can determine adult morphology and fecundity in the barnacle, Semibalanus balanoides. Biofouling 19:205-213

Hills JM, Thomason JC (2003b) The 'ghost of settlement past' determines mortality and fecundity in the barnacle, Semibalanus balanoides. Oikos 101:529-538

Jarrett JN (1997) Temporal variation in substratum specificity of Semibalanus balanoides (Linnaeus) cyprids. J Exp Mar Biol Ecol 211:103-114

> Jeffery CJ (2000) Settlement in different-sized patches by the gregarious intertidal barnacle Chamaesipho tasmanica Foster and Anderson in New South Wales. J Exp Mar Biol Ecol 252:15-26

> Jenkins SR, Murua J, Burrows MT (2008) Temporal changes in the strength of density-dependent mortality and growth in intertidal barnacles. J Anim Ecol 77:573-584 
Johnson LE, Strathman RR (1989) Settling barnacle larvae avoid substrata previously occupied by a mobile predator. J Exp Mar Biol Ecol 128:87-103

> Jonsson PR, Berntsson KM, Larsson AI (2004) Linking larval supply to recruitment: flow-mediated control of initial adhesion of barnacle larvae. Ecology 85:2850-2859

Kent A, Hawkins SJ, Doncaster CP (2003) Population consequences of mutual attraction between settling and adult barnacles. J Anim Ecol 72:941-952

Knight-Jones EW (1953) Laboratory experiments on gregariousness during setting in Balanus balanoides and other barnacles. J Exp Biol 30:584-598

Menge BA (1991) Relative importance of recruitment and other causes of variation in rocky intertidal community structure. J Exp Mar Biol Ecol 146:69-100

> Minchinton TE, Scheibling RE (1993) Free space availability and larval substratum selection as determinants of barnacle population structure in a developing rocky intertidal community. Mar Ecol Prog Ser 95:233-244

Pineda J, Caswell H (1997) Dependence of settlement rate on suitable substrate area. Mar Biol 129:541-548

Pineda J, Riebensahm D, Medeiros-Bergen D (2002) Semibalanus balanoides in winter and spring: larval concentration, settlement, and substrate occupancy. Mar Biol 140: 789-800

Pineda J, DiBacco C, Starczak V (2005) Barnacle larvae in ice: survival, reproduction, and time to postsettlement metamorphosis. Limnol Oceanogr 50:1520-1528

Pineda J, Starczak V, Stueckle TA (2006) Timing of successful settlement: demonstration of a recruitment window in the barnacle Semibalanus balanoides. Mar Ecol Prog Ser 320: 233-237

Raimondi PT (1988) Settlement cues and determination of the vertical limit of an intertidal barnacle. Ecology 69:400-407

Raimondi PT (1990) Patterns, mechanisms, consequences of variability in settlement and recruitment of an intertidal barnacle. Ecol Monogr 60:283-309

Raimondi PT (1991) Settlement behavior of Chthamalus anisopoma larvae largely determines the adult distribu-

Editorial responsibility: Antony Underwood, Sydney, Australia tion. Oecologia 85:349-360

Southward AJ, Crisp DJ (1956) Fluctuations in the distribution and abundance of intertidal barnacles. J Mar Biol Assoc UK 35:211-229

Stamps JA, Krishnan VV (2005) Nonintuitive cue use in habitat selection. Ecology 86:2860-2867

Stamps JA, Krishnan VV, Reid ML (2005) Search costs and habitat selection by dispersers. Ecology 86:510-518

> Svensson CJ, Jenkins SR, Hawkins SJ, Myers AA and others (2004) Models of open populations with space-limited recruitment in stochastic environments: relative importance of recruitment and survival in populations of Semibalanus balanoides. Mar Ecol Prog Ser 275:185-197

> Toonen RJ, Tyre AJ (2007) If larvae were smart: a simple model for optimal settlement behavior of competent larvae. Mar Ecol Prog Ser 349:43-61

Underwood AJ, Denely EJ (1984) Paradigms, explanations and generalizations in models for the structure of intertidal communities on rocky shores. In: Strong DR, Simberloff D, Abele LG, Thistle AB (eds) Ecological communities: conceptual issues and the evidence. Princetown University Press, Princetown, NJ, p 151-180

> Underwood AJ, Fairweather PG (1989) Supply-side ecology and benthic marine assemblages. Trends Ecol Evol 4: $16-20$

Walters LJ, Miron G, Bourget E (1999) Endoscopic observations of invertebrate larval substratum exploration and settlement. Mar Ecol Prog Ser 182:95-108

Wethey DS (1983) Effects of crowding on fecundity in barnacles: Semibalanus (Balanus) balanoides, Balanus glandula, and Chthamalus dalli. Can J Zool 62:1788-1795

- Wethey DS (1984) Spatial pattern in barnacle settlement: day to day changes during the settlement season. J Mar Biol Assoc UK 64:687-698

Wethey DS (1986) Local and regional variation in settlement and survival in the littoral barnacle, Semibalanus balanoides (L.): patterns and consequences. In: Moore PG, Seed R (eds) The ecology of rocky coasts. Columbia University Press, New York, p 194-202

Submitted: March 16, 2009; Accepted: September 6, 2009 Proofs received from author(s): November 8, 2009 